Article

\title{
Factors Affecting Collective Actions in Farmer-Managed Irrigation Systems of Nepal
}

\author{
Tirtha Raj Dhakal *, Brian Davidson and Bob Farquharson \\ Faculty of Veterinary and Agricultural Sciences, University of Melbourne, Parkville 3010, Australia; \\ b.davidson@unimelb.edu.au (B.D.); bob.farquharson@unimelb.edu.au (B.F.) \\ * Correspondence: tdhakal@student.unimelb.edu.au; Tel: +61432306313
}

Received: 22 April 2018; Accepted: 30 May 2018; Published: 2 June 2018

\begin{abstract}
The efficient management of agricultural water to meet its growing demand and to increase farm productivity has become a major concern in many agrarian countries. Various management principles, such as changes in governance, and crafting locally devised institutions have been prioritised in recent literature. The Nepalese government has considered farmers' governance in managing irrigation systems as a successful irrigation policy. One of the measures for a successful farmer-managed irrigation systems (FMIS), each farmer must engage actively in collective choice actions and share both the costs and benefits from the system, proportionately. Various aspects in an institution affects farmers' cooperative behavior to engage in the irrigation management process. A study of 232 FMIS in Nepal revealed that there is a need for a revised institutional design that can empower farmers by investing them with more defined property rights so that they can actively engage in maintenance activities.
\end{abstract}

Keywords: collective actions; farmer-managed irrigation systems; institutional design; Nepal

\section{Introduction}

Irrigation water management is complex because of its attributes, such as the nature of public goods and the lack of properly defined rights for its use. Many of the management issues in irrigation arise because of this, along with the systems suffering from multiple market failures, including those of the monopolistic tendencies associated with singular control authorities (being a natural monopolist) and being fraught with information asymmetries [1,2].

Irrigation water management is reinforced by two schools of thought. The first, provoked by Gordon [3], Olson [4], and Hardin [5], argued that the inclusion of locals in the management of commons would further deplete resources. Their major argument against users' participation was that the overexploitation of such resources might occur in the absence of external forces, giving more priority to the individual rather than societal interests [6]. They advocated for either 'state intervention' or a 'market solution' (privatisation) for the sustainable management of the resources over a long period. The second school of thought arose in the mid-1980s after many scholars, such as Bromley and Cernea [7], Gardner, et al. [8], and Ostrom [9], undertook substantial case studies from various parts of the world. These scholars concluded that better water allocation and management of irrigation resources resulted from the active involvement of local user groups with both improved water allocations in the systems and overall management of the irrigation resources compared to centrally managed systems. Thus, a community-based participatory approach is used by major instrumental policies in various developing countries.

Many past studies of irrigation management in Nepal have concluded that farmer-managed irrigation systems (FMIS) are more successful than centralized systems [10-12]. In FMIS, cooperation among the beneficiaries is essential for the successful management of irrigation schemes. However, 
different physical characteristics (such as canal lengths, the lining of the canals, the distance from water resources, and socio-economic attributes such as farmers' income, farm size), and the types of institutional arrangements adopted may affect the incentives for users to engage in cooperative behaviors. The aim of this paper is to identify the different aspects that affect farmers' cooperative behaviors that lead to the successful management of irrigation resources in Nepal. Successful management in this study is defined as one which leads to the system being maintained adequately and a high level of trust amongst the beneficiaries. To accomplish this, secondary data from 232 Nepalese FMIS, recorded in the Nepal Irrigation Institutions and Systems (NIIS) database has been analyzed. In this study, a regression analysis has been employed to determine the significant factors that can affect farmers' incentives to engage in collective actions.

\section{Review of Irrigation Development in Nepal}

Before the mid-1950s, many irrigation infrastructures in Nepal were constructed and managed by farmers. These were small, traditional infrastructures. State involvement in such infrastructure development was limited, and few budgetary resources were allocated for the construction and maintenance of the royal canals (raj kulos) [13,14]. After the 1960s, Nepal received much attention from international donor agencies, such as the World Bank and the Asian Development Bank, which was mostly directed at improving and expanding medium- and large-scale projects. All of these projects were supply driven and centrally managed. The beneficiaries' involvement and their actual needs were ignored. All responsibilities, such as the operation and maintenance (O\&M) of the schemes and the water distribution in command areas, were vested in government officials. Relative to their substantial investment, these centralised schemes did not bring satisfactory results [15], and the agricultural production of the country did not increase as expected.

Since the 1990s, the Government of Nepal has made an effort to improve irrigation water supplies, as well as the maintenance of the infrastructure, by including local communities as important stakeholders in the overall management and decision-making processes. Water User Groups (WUG) and Irrigation Management Transfer (IMT) programs were developed in this process of reform. With the introduction of IMT programs, the management of medium and some large irrigation projects were handed over from the government to local farmers' groups.

Two distinct types of irrigation systems exist in Nepal. One is a management system controlled by a central authority and the other is the decentralised irrigation system, which is managed by a group of farmers or their associations. Agency-managed irrigation systems (AMIS), which are centralised and managed by the Department of Irrigation (DOI), are usually larger and have better engineering when compared to traditionally constructed FMIS. However, according to the Department of Irrigation [16], the FMIS is the most preferred form of managing an irrigation system in Nepal, and is practised in approximately two-thirds of the total surface irrigated area.

These two forms of governance mainly differ in the ways in which roles are assigned to local users. Many case studies from Nepal [10-12] have reported positive outcomes from the participation of local users and their organisations in the overall management of irrigation resources. FMIS have outperformed the AMIS in terms of agricultural productivity, water distribution, fee collection rates, and the overall maintenance of the system. Thus, a change of governance from AMIS to FMIS has been prioritised by the Nepalese government as an alternative solution for many low-performing public irrigation systems in Nepal [17].

The number of positive impacts brought by the change in governance in the irrigation sector of Nepal is well established $[12,18,19]$. However, the identification of the key aspects that result in farmers engaging in collective actions for achieving successful irrigation resource management has not yet been explored. The incentive for any individual to participate in the management of irrigation systems depends on how fairly the costs and benefits are distributed among them. Costs and benefits shared between headenders (farmers of the head part of an irrigation scheme) and tailenders (farmers of the bottom part of an irrigation scheme) of an irrigation scheme may differ because of various aspects, such 
as canal length, engineering structure of the system, and the institutional arrangements. Understanding such key aspects would help policy makers consider alternative institutional arrangements that may induce more incentives for beneficiaries to engage in collective actions by proportionate sharing of both cost-benefits among them.

\section{Materials and Methods}

The problems with any irrigation systems can be site specific. Thus, it is necessary to analyse various attributes that can shape the various situations in which collective actions occur in order to identify these problems. The decision by farmers to participate collectively in managing irrigation systems is generally structured into three sets of contextual attributes [20], as seen in Figure 1. These sets of attributes that create different incentives and constraints to participate in collective management are:

i. Physical attributes of the irrigation system,

ii. Socio-economic attributes of the participants, and

iii. Existing institutional arrangement practiced by the participants.

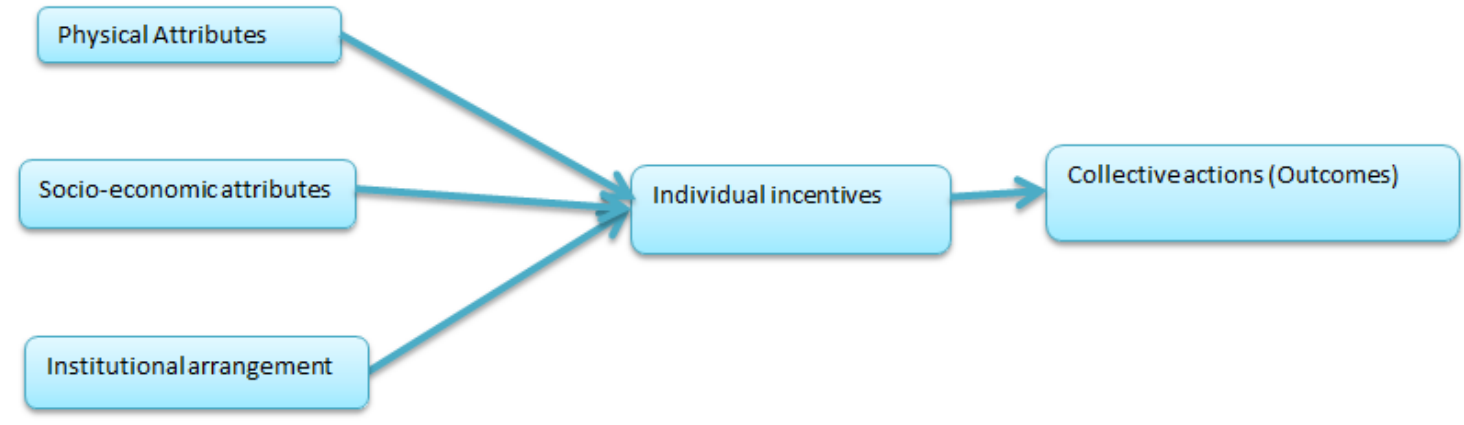

Figure 1. Institutional Analysis Framework. Source: Ostrom [20].

The number of physical, socio-economic, and institutional attributes can affect the incentives for irrigators to involve themselves in collective action for the purpose of managing irrigation resources. Among these attributes, the engineering structure of the irrigation scheme-such as types of headwork (whether it is permanent or temporary) and canal lining, well-defined boundaries for the irrigation system, institutional arrangements for sanctioning and labour mobilization for the maintenance of resources, economic heterogeneity among users, and economic efficiency of the irrigation system. These attributes can be regressed against measures of the quality of resource maintenance and the level of mutual trust among the users. The purpose of conducting a regression analysis was to analyse which of these different attributes would influence the collective actions of the irrigators in the management of irrigation systems.

To undertake this analysis, the secondary source of data recorded on the NIIS database was used. This database was jointly developed by Ostrom and her colleagues from Indiana University and by the Irrigation Management Systems Study Group at the Institute of Agriculture and Animal Science, Tribhuvan University in Nepal. The purpose of this database was to record information on the various aspects of the community and institutional arrangements of the irrigation systems in Nepal, including their physical attributes [21]. The initial database contained information on 127 irrigation systems. An effort to increase the number of cases continues and this database now contains information on 255 irrigation systems (including both FMIS and AMIS). Out of 255 systems, 20 are AMIS; these were excluded from this study. Further, three FMIS were not included in the study due to data lags. Consequently, a total of 232 irrigation systems cases were accounted for in this study.

Most factors that affect the incentives for an irrigator to engage in cooperative behavior towards resource management are categorical variables. Therefore, an ordinal regression analysis was conducted. 
Two dependent variables, the level of maintenance of the irrigation resource and the mutual trust among the appropriators, were used as indicators for creating incentives for collective action situations among them. These variables, and their levels of measurement, are given in Table 1.

Table 1. Description of variables used in the ordinal analysis.

\begin{tabular}{|c|c|c|}
\hline Description of Variables & Types & Level of Measurement \\
\hline Maintenance of resource & Dependent & $\begin{array}{l}1=\text { Well maintained } \\
2=\text { Moderately Maintained } \\
3=\text { Insufficient Maintenance } \\
4=\text { Poor or no maintenance }\end{array}$ \\
\hline Level of mutual trust among beneficiaries & Dependent & $1=$ High, $2=$ Medium, $3=$ Low \\
\hline $\begin{array}{l}\text { Nature of headwork } \\
\text { Canal lining } \\
\text { Presence of alternative water supply source } \\
\text { Basis of labour mobilization } \\
\text { Social sanction } \\
\text { Fine in monetary value } \\
\text { Number of appropriators using the resources } \\
\text { Well-defined rights and duties of users } \\
\text { Economic Efficient i.e., in short term, benefits } \\
\text { exceed the operation and maintenance costs }\end{array}$ & Independent & $\begin{array}{l}\text { Temporary }=0 \text {, Permanent }=1 \\
\text { No lining = } 0 \text {, Lining = } 1 \\
\text { No }=0 \text {, Yes }=1 \\
1=\text { Land basis, } 2=\text { Water allocation, } 3=\text { Equal participation, } \\
4=\text { Voluntary } \\
1=\text { Likely, } 2=\text { Unlikely } \\
1=\text { Likely, } 2=\text { Unlikely } \\
1=<25,2=25-49,3=50-99,4=100-200,5=201-500,6=>500 \\
0=\text { No, } 1=\text { Yes } \\
1=\text { Efficient } 2=\text { Inefficient }\end{array}$ \\
\hline Variance of income among the appropriators & & $1=$ Low, $2=$ Moderate, $3=$ High \\
\hline
\end{tabular}

\subsection{The Independent Variables-Mutual Trust and the Level of Maintenance}

In determining the capability of any FMIS to function well, two elements would appear to be most crucial; mutual trust amongst the beneficiaries and the ability to maintain a level of service to those beneficiaries. The first issue in any cooperative system revolves around trust. Do those who benefit trust one another? If the trust is not there, then it would seem that any cooperation is not possible. It would defeat the whole purpose of the policy move towards FMIS. It should be noted that in a centralized system this is not an issue as the beneficiaries have the powers of the state to gain the cohesion required to keep others in line. The NIIS collects data on each irrigation scheme, reporting that three levels of trust; high, medium and low.

Ultimately beneficiaries are interested in maintaining a steady supply of water, something that is only possible if the infrastructure is well maintained. Thus, the degree of maintenance is a measure of how well FMIS operate. The NIIS collects data on the maintenance of the resource, segregating it into poor or non-existent, insufficient, moderately or well maintained. Maintenance of irrigation systems is critical during high water requirement periods. These periods mostly occur during the "paddy growing and pre-monsoon season".

Two different types of maintenance activities occur in many FMIS. The regular maintenance activities that are carried out in regular time periods such as beginning of the cropping seasons or monsoon season include de-silting of major branch canals, repairs of headworks, and cutting grasses and cleaning whole main and branch canals. Then there is the emergency repair and maintenance are carried out when there is sudden disturbance in the flow of water in the canals. This may be due to natural disasters such as floods and landslides; sometimes it is due to development activities such as road construction.

\subsection{Independent Variables}

\subsubsection{Maintenance and Labour Mobilisation}

In most FMIS, labour constitutes the major source for regular and annual maintenance of irrigation systems. Therefore, labour mobilisation could well be crucial for the efficient management of irrigation resources. Different irrigation systems have different bases for labour mobilisation. According to NIIS, four different bases for labour mobilisation have been found (Table 2). The size of land holding has 
been found as the primary basis of labour supply followed by equal participation from each household, regardless of irrigated area and amount of water delivery. Water allocation times (hours) and voluntary participation are other forms of labour mobilization in some FMIS. Alternate arrangements such as collection of funds from the appropriators and amount from the sanctions are also significant sources in regular maintenance.

Two different types of maintenance activities have been found in many FMIS. The regular maintenance activities that are carried out in regular time periods, such as the beginning of the cropping seasons or monsoon season, include de-silting of major branch canals, repairs of headworks, and the cutting of grasses and cleaning of whole main and branch canals. Emergency repair and maintenance are carried out when there is a sudden disturbance in the flow of water in the canals. This may be due to natural disasters, such as floods and landslides; sometimes it is due to development activities, such as road construction.

Table 2. Basis of labour mobilisation $(n=212)$.

\begin{tabular}{ccc}
\hline Labour Mobilisation Basis & Frequency & $\mathbf{\%}$ \\
\hline Land-holding & 122 & 57.5 \\
Equal participation & 84 & 39.6 \\
Water Allocation & 5 & 2.4 \\
Voluntary & 1 & 0.5 \\
\hline
\end{tabular}

\subsubsection{Water Allocation and Distribution Arrangement}

Two types of water sharing arrangements can be found in irrigation systems: Intersystem and intra-system. An intersystem water sharing arrangement is common among irrigation systems that feature multiple irrigation systems drawing water from the same source. The basis for water allocation in such systems is the mutual consensus among the users. For example, Yampa Phant Irrigation systems and the Satrasaya Phant Irrigation System of Tanahun use the same source of water from the Andimul stream. There has been certain diversion of structures to allocate water in two different irrigation systems. However, during water deficit seasons, mainly during the pre-monsoon season, stealing water by breaching the diversion structures has always remained a potential source of conflict between users of the two different irrigation systems. The ability to reduce this antisocial behavior depends on whether monetary fines or social sanctions are applied.

Within a single irrigation system, which is referred to as an intra-system sharing management, a water allocation system reflects entitlements, or rights, to use that are usually defined by the physical boundary of the resource. Many FMIS have clearly defined physical boundaries (Table 3). A physical boundary is usually defined as the area to be irrigated under the irrigation systems. However, in most FMIS, users have no clear boundaries of rights and responsibilities to use it and, therefore, share the costs and benefits from it.

Table 3. Well defined physical boundaries $(n=224)$.

\begin{tabular}{ccc}
\hline Defined Physical Boundaries & Frequency & $\mathbf{\%}$ \\
\hline Yes & 216 & 96.4 \\
No & 8 & 3.6 \\
\hline
\end{tabular}

The water distribution within defined boundaries can take a number of forms, usually decided by the irrigation community [22]. Free flow until saturation of land, timed rotation, and rotation per land holding size are common principles that are followed to distribute water within the defined command area. In most cases, farmers have transferability rights to exchange their entitlements among them. 


\subsubsection{Engineering Structures: Headworks and Canal Linings}

Headworks and canals are important basic structures for diverting water toward cultivated areas. Headworks can be permanent or temporary. Permanent structures, which usually include concrete dams and weirs, can divert water in more controlled ways with less effort because of adjustment devices fitted onto them. Most permanent headworks can be seen in AMIS. Temporary headworks are usually built with local raw materials, such as boulders and wood. These structures are easily washed away by the high pressure of water in the canals. Many of the small- and medium-sized FMIS have this type of headwork. Almost $68 \%$ of the FMIS included in this study have temporary headworks (Table 4). This requires extensive labour to build and maintain, which can improve the bargaining power of the tailenders against headenders. This may help in nurturing mutual dependencies between farmers of two groups at opposite ends of an irrigation scheme, and may improve water delivery across the scheme.

Linings of the canals are closely related with water delivery efficiency. If the canals are lined, delivery efficiency can be improved because lessened seepage and conveyance losses are reduced. Thus, a greater volume of water is available in the systems. The linings can also improve the water availability to the tailenders in the system. This can reduce conflict among users by reducing scarcity problems faced by tail farmers. More than $50 \%$ of FMIs have some form of lined canals (Table 4 ).

Table 4. Nature of Headworks and Canal Lining in FMIS $(n=228)$.

\begin{tabular}{lcc}
\hline Nature of Physical Structures & Frequency & \% \\
\hline Headworks: & & \\
Permanent & 157 & 68.9 \\
Temporary & 71 & 31.1 \\
Canal lining & & \\
Lining & 121 & 53.1 \\
No lining & 107 & 46.9 \\
\hline
\end{tabular}

\subsubsection{Water Supply Status}

Average access to irrigation water supply throughout the year and the presence of alternative water sources among the beneficiaries are other physical attributes that can have an impact upon cooperation among the users. More than $69 \%$ of irrigation schemes have at least a nine-month water supply in a particular year. About $8 \%$ of irrigation schemes reach their maximum water supply period of three months or less (Table 5).

Table 5. Average water supply period within schemes $(n=228)$.

\begin{tabular}{ccc}
\hline Water Supply Period (Months) & Frequency & $\mathbf{\%}$ \\
\hline$<3$ & 18 & 7.9 \\
$4-8$ & 51 & 22.4 \\
$>9$ & 159 & 69.7 \\
\hline
\end{tabular}

The cooperation among users may be influenced by the availability of resources and the degrees of users' dependency on them. The users generally show high level of cooperative behavior in situations where they have no other alternative source of water supply. Over $65 \%$ of FMIS of Nepal have no alternative source of water supply (Table 6). This suggests that farmers must engage in cooperative activities in maintaining irrigation systems to achieve efficient water distribution in the systems. 
Table 6. Alternative source of water with in command area $(n=210)$.

\begin{tabular}{ccc}
\hline Alternative Water Source & Frequency & $\boldsymbol{\%}$ \\
\hline Yes & 73 & 34.8 \\
No & 137 & 65.2 \\
\hline
\end{tabular}

\subsubsection{Economic Efficiency of the Irrigation System}

The variable- economic efficiency of the irrigation system- is used to describe the short term financial efficiency of irrigation systems where they are financially efficient. This means that benefits received by appropriators using the resources exceed the costs for them. Benefits are usually determined in terms of agricultural productivity, and costs concern the labour and monetary inputs for keeping resources in operational condition. Achieving economic efficiency indicates maintenance of the quality of irrigation resources.

\subsubsection{Economic Heterogeneity among Beneficiaries}

The existence of economic heterogeneity, measured by the variance in the economic status of the beneficiaries in the society, among the appropriators is another important factor affecting the collective management of irrigation resources. Wealthy farmers are economically in a stronger position and are not enthusiastic about cooperating with farmers with lower incomes. Also, because of their stronger position, wealthier farmers usually claim an altogether disproportionally larger share of the collective benefits, and bear a similar or lesser share of costs when compared with poorer farmers. This in fact discourages less-wealthy farmers from participating actively in maintenance activities.

Among these attributes, engineering structures, such as the type of headwork (permanent or temporary) and canal lining, sanctioning mechanism as monetary fines or social sanctions, well-defined boundaries for the irrigation system, labour mobilization for the maintenance of resources, economic variances of irrigators, and the economic efficiency of the irrigation system were regressed against the quality of the resource maintenance and mutual trust among the users.

\section{Results}

Regression outputs for the different factors responsible for creating incentives among the irrigators, as well as the mutual trust among irrigators, to cooperate with each other in managing irrigation resources in the FMIS of Nepal is presented in Table 7.

Table 7. Ordinal regression results for the maintenance of resources and mutual trust.

\begin{tabular}{ccc}
\hline & Maintenance of Resources & Mutual Trust \\
\hline Variables & Coefficient & Coefficient \\
Constant & $10.671^{* * *}$ & $6.153^{* *}$ \\
Headwork & -0.004 & $-1.412^{* *}$ \\
Canal lining & $0.874^{* *}$ & $1.026^{* *}$ \\
Size of appropriators & -0.172 & -0.162 \\
Labour Mobilization & -0.123 & -0.115 \\
Social sanctions & -0.091 & -0.573 \\
Monetary fine & $0.958^{* *}$ & -0.224 \\
Well defined rights & $-1.819^{* *}$ & 1.398 \\
Variance of the income & $-0.760^{* * *}$ & $1.315^{* *}$ \\
Economic efficiency & $4.0948^{* * *}$ & $1.225^{* * *}$ \\
Pseudo $R^{2}$ & 0.57 & 0.527 \\
\hline
\end{tabular}

Note: ${ }^{* *} p<0.05,{ }^{* * *} p<0.01$. 
Out of the two important physical attributes, headwork and canal lining, included in the analysis, the canal lining was found to be positively significant in creating incentives in irrigators to engage in the maintenance of resources, as well as in keeping mutual trust among them. Lining canals improves water delivery to the tail portion of the irrigation system, thereby, improving irrigation performance [12]. In contrast to this, Bardhan [23] found a negative relationship between the lining and the maintenance of resources while studying 48 irrigation systems in India, which he called 'surprising'.

Maintenance activities become collective endeavors among appropriators when extensive labour is required, as in the case of the temporary headworks. Lam [12] argued that an irrigation system with permanent headwork structures requires less labour for maintenance of the irrigation system and also reduces the bargaining power of tailenders. However, the statistically insignificant headwork variable in the regression output is indicative of the fact that permanent headwork structures are not significant factors in creating incentives among beneficiaries. Permanent headwork structures reduce mutual trust among participants, as indicated by the negative, but statistically significant, coefficient of headwork with mutual trust.

Institutional arrangements, such as sanctioning mechanisms and labour mobilization, affect irrigators' cooperative behaviour to engage collectively. Sanctioning rule-breakers can have important impacts on farmers' cooperation activities. Sanctions help to enforce the rules and discourage farmers from theft or intentional leakage of water into their farms. This encourages farmers to maintain the resources and obey the rules. The results of this study suggest that monetary fines are statistically and positively significant when creating incentives among users in resource maintenance; however, fines are insignificant for creating mutual trust among users. Similarly, social sanctions were found to be insignificant and undermine the creation of mutual understanding in managing resources. This is probably because social sanctions may create humiliation among the sanctioned individuals, therefore, discouraging them from participating in maintenance activities. Similarly, the size of appropriators and labour mobilization in FMIS were found to be statistically insignificant. Lam [12] and Tang [24] found a similar insignificant relationship between the size of appropriators and a measure of the performance of the irrigation systems.

The well-defined physical boundaries of the irrigation resource as well as the right of appropriators to share both the costs and benefits for it are also important factors in collective action situations. The estimates in this study suggest that the well-defined variable has negative but are statistically significant with resource maintenance. This indicates that there is a disproportionate sharing of the costs and benefits among headenders and tailenders from utilizing the resources. More than $95 \%$ of irrigation systems included in this study have clearly defined physical boundaries, however, there is a lagging of appropriate institutional arrangements for defining users' rights and responsibilities towards proportionate sharing of both the costs and benefits from the resource. In any irrigation system, headenders may always appropriate more benefits because of their physical location. The water quality and quantity deteriorates as it flows toward the tail portion of irrigation schemes. However, tailenders pay the same service fees and engage in similar maintenance activities to headenders, even though inequalities exist in the benefits received from the utilisation of the resources. Under well-defined resources, the appropriators have proportionated cost-benefit sharing mechanisms that create incentives for farmers to engage in collective actions. The lack of clear mechanisms to share proportionate benefits and costs among users may discourage appropriators from participating in collective arrangements.

In this study, economic heterogeneity was found to be statistically significant, with a negative coefficient in the relationship with dependent variable-maintenance of resources; but a positively significant relationship with dependent variable-mutual trust. The results suggest that systems with significant income disparities face difficulties in engaging in collective activities. Other studies, such as Bardhan [23], reported that income disparity among farmers is one of the major factors for poor maintenance of the irrigation system in India. Lam [12] also found similar results with agricultural productivity in Nepal. Wealthy farmers are economically in a stronger position and are not enthusiastic 
about cooperating with farmers that have lower incomes. Also, because of their stronger position, wealthier farmers usually claim a disproportionally larger share of the collective benefits, and bear a similar or lesser share of the costs, when compared with poorer farmers. This fact discourages less-wealthy farmers from participating actively in maintenance activities. The positive relationship between heterogeneity and mutual trust in this study seems ambiguous. Generally, higher levels of mutual trust can be found in similar economic groups and vice-versa.

The variable economic efficiency of the irrigation system was found to be positively and statistically significant, indicating that, among those irrigation systems where operation and maintenance costs were recovered, farmers were actively engaging to keep the resources in a good working condition. With respect to mutual trust among the users, economic efficiency of irrigation systems was found to be positively and statistically significant. This indicates that, in the systems where farmers have mutual understandings among themselves, they are actively engaged in collective situations to keep the resources in full operational condition.

\section{Discussion and Conclusions}

The government of Nepal has recognised that maintaining agricultural growth is an important strategy for reducing the country's poverty [25]. Agricultural water can, therefore, play a crucial role in increasing farm productivity and addressing the country's food deficit situation. With better management of the irrigation sector, the country can boost the productivity of cereal crops six fold [26]. The irrigation sector, therefore, has attracted significant investment in infrastructure development and for the rehabilitation of existing ones [27].

The findings of this study suggest that engineering innovations alone do not necessarily improve the performance of irrigation resources; nor is investing in such innovations able to solve the problems that the sector is currently facing. The construction of permanent headworks in many FMIS has brought inequality among headenders and tailenders, which ultimately reduces the bargaining power of the tailenders. This was also found to have a negative impact on the mutual trust among users. Appropriators, mainly from the tail portion of irrigation, have fewer incentives to participate in collective action situations. Though engineering infrastructures provide better water delivery to farms and improves agricultural productivity, effective institutions are essential to keep such infrastructures in reasonable working conditions and ensure efficient distribution of resources among appropriators.

Many FMIS are seen to be economically efficient in the short run. But, for long-lived institutions and resource maintenance, there must be a proportionate sharing of the costs and benefits among users [9]. For this to occur, alternative institutional arrangements may well need to be devised that reduce disproportionate sharing of the costs and benefit among the appropriators. This may create incentives among all appropriators for collective actions in the efficient management of irrigation resources. The existing institutional arrangement adopted in Nepal does not favor proportionate sharing of the costs and benefits among users. As a result, the Nepalese irrigation sector is facing some water-related issues. First, water use efficiency is quite low in both FMIS and AMIS [27]. According to the National Water Plan [28], overall, low water use efficiency is less than $30 \%$, indicating that a huge quantity of water is not being significantly used in the production process. Institutional arrangements about practice are unable to provide any incentives to control unnecessary usage in the fields. Furthermore, seepage and conveyance losses have reduced water productivity. Second, the reliability of water flow in the schemes is quite poor. Farmers do not have enough information about the time and frequency of water supply in the schemes. Rogers, et al. [29] argued that this type of uncertainty on the quantity of water supplies in the schemes in South Asian countries has become the major determinant for low agricultural production. Third, water charging methods as well as proper collection and mobilization of irrigation service fee have always been a great problem in the proper maintenance of Nepal's irrigation systems. Nepal is currently adopting an area-based pricing policy [30] where irrigators are charged, irrespective of the amount of water they consume. This method of irrigation pricing is easy to implement, but it is also likely to lead overconsumption 
of water [31]. The pricing mechanism that is currently practiced has two major disadvantages. First, water is not priced according to the quantity, so there is no incentive to use it properly. Thus, farmers who are mainly from tail regions suffer the disproportionate sharing of the benefits and costs. In the current institutional arrangement, costs are shared almost equally among all users, but headenders usually share larger portions of the benefits. Second, it does not generate sufficient funds for the cost recovery of irrigation schemes [19]. Thus, the system may be operating at a sub-optimal level because of poor collection and mobilization of funds.

Finally, unequal distribution of the costs and benefits among tailenders and headenders has become an important issue in the collective management of shared resources. The findings suggest that, even though there is the right for both tailenders and headenders to use resources, unequal sharing of the costs and benefits that exists in many FMIS of Nepal has discouraged farmers from becoming actively involved in communal work. Because of their physical location, headenders always have a greater chance of receiving higher benefits when compared to tailenders. The inadequate and unpredictable water supply to the tail region of Nepal's irrigation systems usually discourages tailenders from pursuing collective actions. This, ultimately, reduces the functional level of irrigation systems, thus, entailing that resources cannot be efficiently managed and distributed.

An institutional arrangement, with a clear set of specific rules, is essential for the sustainability of the commonly shared resources, such as irrigation water [32]; and system performance is truly based on how well these institutions are designed and implemented. Thus, irrigation water management is more a socio-economic phenomenon than one of engineering design [33]. The need for alternative institutional arrangements has been identified as a major instrument for managing most of the irrigation problems faced by Nepal. However, changes in existing structures incur some costs that need to be compared with the likely benefits of the improved water supply. Therefore, it will be essential to consider the likely transaction costs for the implementation of any changes in structures and the likely benefits from such changes. Future research should, therefore, focus on the transaction costs involved in devising alternate institutions to make local institutions more robust and sustainable over a long period.

Author Contributions: T.R.D conducted the analysis through MATLAB and developed the concept of paper, B.D re-organized the writing of the paper, and BF contributed on contents and literature review section.

Acknowledgments: This paper was constructed as a part of corresponding author's Ph.D. project in University of Melbourne with Post Graduate Scholarship from the Endeavour Australia Awards.

Conflicts of Interest: The authors declare no conflict of interest.

\section{References}

1. Davidson, B. The Problems of Analysing Markets for Irrigation Water; The Australian Agricultural Economics and Resource Society: Melbourne, Australia, 2004.

2. Hanemann, W.M. The economic conception of water. Water Crisis Myth Reality 2006, 61, 74-76.

3. Gordon, H.S. The economic theory of a common-property resource: The fishery. J. Political Econ. 1954, 62, 124-142. [CrossRef]

4. Olson, M. The Logic of Collective Action: Public Goods and the Theory of Groups; Cambridge University Press: Cambridge, MA, USA, 1965.

5. Hardin, G. The tragedy of the commons. Science 1968, 162, 1243-1248. [CrossRef] [PubMed]

6. Sarker, A.; Itoh, T. Design principles in long-enduring institutions of Japanese irrigation common-pool resources. Agric. Water Manag. 2001, 48, 89-102. [CrossRef]

7. Bromley, D.W.; Cernea, M.M. The Management of Common Property Natural Resources: Some Conceptual and Operational Fallacies; World Bank Publications: Washington DC, USA, 1989; Volume 57.

8. Gardner, R.; Ostrom, E.; Walker, J.M. The nature of common-pool resource problems. Ration. Soc. 1990, 2, 335-358. [CrossRef]

9. Ostrom, E. Governing the Commons: The Evolution of Institutions for Collective Action; Cambridge University Press: Cambridge, MA, USA, 1990. 
10. Bastakoti, R.C.; Shivakoti, G.P.; Lebel, L. Local irrigation management institutions mediate changes driven by external policy and market pressures in Nepal and Thailand. Environ. Manag. 2010, 46, 411-423. [CrossRef] [PubMed]

11. Bhatta, K.P.; Ishida, A.; Taniguchi, K.; Sharma, R. Performance of agency-managed and farmer-managed irrigation systems: A comparative case study at Chitwan, Nepal. Irrig. Drain. Syst. 2006, 20, 177-191. [CrossRef]

12. Lam, W.F. Improving the performance of small-scale irrigation systems: The effects of technological investments and governance structure on irrigation performance in Nepal. World Dev. 1996, 24, 1301-1315. [CrossRef]

13. Regmi, M.C. Thatched Huts and Stucco Palaces: Peasants and Landlords in 19th-Century Nepal; Vikas Publishing House Private: New Delhi, India, 1978; Volume 1.

14. Shah, S.G.; Singh, G.N. Irrigation Development in Nepal: Investment, Efficiency and Institution; Winrock International: Kathmandu, Nepal, 2001.

15. NPC. Irrigation Development in Retrospect: Search for a Breakthrough; National Planning Commission: Kathmandu, Nepal, 1994.

16. Department of Irrigation. Non Conventional Irrigation Technology Project. Available online: http://www. doi.gov.np/about/ (accessed on 3 December 2015).

17. Irrigation Policy. Sinchai Niti, 2070 (Nepali); Ministry of Irrigation: Kathmandu, Nepal, 2014.

18. Vermillion, D.L. Impacts of Irrigation Management Transfer: A Review of the Evidence; International Irrigation Managemetn Institute: Colombo, Sri Lanka, 1997; Volume 11.

19. Mishra, V.; Molden, D.J. Management Turnover in the West Gandak Irrigation System, Nepal; IWMI: Colombo, Sri Lanka, 1996.

20. Ostrom, E. Institutional Analysis, Design Principles and Threats to Sustainable Community Governance and Management of Commons; International Center for Living Aquatic Resources Management: Manila, Philippines, 1994; pp. 34-50.

21. NIIS Research Team. Project: Nepal Irrigation Institutions and Systems Database Coding Sheets and Forms; Indiana Univesity, Workshop in Political Theory and Policy Analysis: Bloomington, IN, USA, 1993.

22. Pradhan, P. Patterns of Irrigation Organization in Nepal: A Comparative Study of 21 Farmer-Managed Irrigation Systems; IWMI: Colombo, Sri Lanka, 1989.

23. Bardhan, P. Irrigation and cooperation: An empirical analysis of 48 irrigation communities in south India. Econ. Dev. Cult. Chang. 2000, 48, 847-865. [CrossRef]

24. Tang, S.Y. Institutions and Collective Action in Irrigation Systems. PhD Thesis, Indiana University, Bloomington, IN, USA, 1989.

25. ADB. Sector Assessment (Summary): Irrigation Nepal: Community Irrigation Project. Available online: https: / / www.adb.org/sites/default/files/linked-documents/38417-02-nep-ssa.pdf (accessed on 13 March 2016).

26. IRIN. “Dismal” irrigation system worsens crop shortages. Integrated Regional Information Networks, 7 January 2011.

27. World Bank. Irrigation and Water Resource Management; World Bank: Kathmandu, Nepal, 2014.

28. National Water Plan. National Water Plan; Ministry of Energy: Kathmandu, Nepal, 2005.

29. Rogers, P.; De Silva, R.; Bhatia, R. Water is an economic good: How to use prices to promote equity, efficiency, and sustainability. Water Policy 2002, 4, 1-17. [CrossRef]

30. Easter, K.W.; Liu, Y. Cost Recovery and Water Pricing for Irrigation and Drainage Projects; World Bank, Agriculture and Rural Development: Washington DC, USA, 2005.

31. Easter, K.W.; Liu, Y. Who pays for irrigation: Cost recovery and water pricing? Water Policy 2007, 9, $285-303$. [CrossRef]

32. Ostrom, E. Institutions and the environment. Econ. Aff. 2008, 28, 24-31. [CrossRef]

33. Crase, L.; Gandhi, V.P. The effectiveness of water institutions. In Reforming Institutions in Water Resource Management: Policy and Performance for Sustainable Development; Crase, L., Gandhi, V.P., Eds.; Earthscan: London, UK, 2009; pp. 3-19.

(C) 2018 by the authors. Licensee MDPI, Basel, Switzerland. This article is an open access article distributed under the terms and conditions of the Creative Commons Attribution (CC BY) license (http:/ / creativecommons.org/licenses/by/4.0/). 